\title{
The influence of sensitisation to pollens and moulds on seasonal variations in asthma attacks
}

\author{
Cristina Canova', Joachim Heinrich², Josep Maria Anto ${ }^{3,4,5,6}$, Benedicte Leynaert ${ }^{7}$, \\ Matthew Smith ${ }^{8}$, Nino Kuenzli $i^{9,10}$, Jan-Paul Zock ${ }^{3,4,5}$, Christer Janson ${ }^{11}$, Isa Cerveri ${ }^{12}$, \\ Roberto de Marco ${ }^{13}$, Kjell Toren ${ }^{14}$, Thorarinn Gislason ${ }^{15}$, Dennis Nowak ${ }^{16}$, \\ Isabelle Pin ${ }^{17}$, Matthias Wjst ${ }^{18}$, Jure Manfreda ${ }^{19}$, Cecilie Svanes ${ }^{20}$, Julian Crane ${ }^{21}$, \\ Michael Abramson ${ }^{22}$, Michael Burr ${ }^{23, \dagger}$, Peter Burney ${ }^{1}$ and Deborah Jarvis ${ }^{1}$
}

\begin{abstract}
Affiliations: ${ }^{1}$ Respiratory Epidemiology and Public Health and MRC-HPA Centre for Environment and Health, National Heart and Lung Institute, Imperial College, London, and ${ }^{23}$ Dept of Primary Care and Public Health, Cardiff University, Cardiff, UK. ${ }^{2}$ Helmholtz Center Munich, German Research Center for Environmental Health, Neuherberg, ${ }^{16}$ Institute and Outpatient Clinic for Occupational, Social and Environmental Medicine, Ludwig-Maximilians-University, Munich, and ${ }^{18}$ Institute of Lung Biology and Disease, CPC - Comprehensive Pneumology Center, Helmholtz Center Munich - German Research Center for Environmental Health, Munich, Germany. ${ }^{3}$ Centre for Research in Environmental Epidemiology (CREAL), Barcelona, ${ }^{4} \mathrm{Hospital}$ del Mar Research Institute (IMIM), Barcelona, ${ }^{5} \mathrm{CIBER}$ Epidemiología y Salud Pública (CIBERESP), Barcelona, and ${ }^{6} \mathrm{Dept}$ of Life and Experimental Sciences, Universitat Pompeu Fabra, Barcelona, Spain. ${ }^{7}$ National Institute of Health and Medical Research, INSERM Unit 700, Paris, and ${ }^{17} \mathrm{CHU}$ de Grenoble, INSERM, U823, Institut Albert Bonniot, University Joseph Fourier, Grenoble, France. ${ }^{8}$ Dept of Oto-Rhino-Laryngology, Research Unit Aerobiology and Pollen Information, Medical University of Vienna, Vienna, Austria. ${ }^{9}$ University of Basel, Basel, and ${ }^{10}$ Swiss Tropical and Public Health Institute (Swiss TPH), Basel, Switzerland. "1'Dept of Medical Sciences, Respiratory Medicine and Allergology, Uppsala University, Uppsala, and ${ }^{14}$ Section of Occupational and Environmental Medicine, Institute of Medicine, University of Gothenburg, Gothenburg, Sweden. ${ }^{12}$ Clinica di Malattie dell'Apparato Respiratorio. Fondazione Ricovero e Cura a Carattere Scientifico Policlinico S. Matteo, Università di Pavia, Pavia, and ${ }^{13}$ Unit of Epidemiology and Medical Statistics, Dept of Medicine and Public Health, University of Verona, Verona, Italy. ${ }^{15}$ Faculty of Medicine, University of Iceland, Reykjavik, Iceland. ${ }^{19}$ Dept of Medicine, University of Manitoba, Winnipeg, Canada. ${ }^{20}$ Institute of Medicine, University of Bergen, Bergen, Norway. ${ }^{21}$ Wellington Asthma Research Group, University of Otago, Wellington, New Zealand. ${ }^{22}$ Epidemiology and Preventive Medicine, Monash University, Melbourne, Australia.
\end{abstract}

Correspondence: D. Jarvis, Respiratory Epidemiology and Public Health, Imperial College, London, Emmanuel Kaye Building, Manresa Road, London, SW3 6LR, UK. E-mail: d.jarvis@imperial.ac.uk

ABSTRACT No large study has described the seasonal variation in asthma attacks in population-based asthmatics in whom sensitisation to allergen has been measured.

2637 young adults with asthma living in 15 countries reported the months in which they usually had attacks of asthma and had skin-prick tests performed. Differences in seasonal patterns by sensitisation status were assessed using generalised estimating equations.

Most young adults with asthma reported periods of the year when their asthma attacks were more common (range: $47 \%$ in Sweden to $86 \%$ in Spain). Seasonal variation in asthma was not modified by sensitisation to house dust mite or cat allergens. Asthmatics sensitised to grass, birch and Alternaria allergens had different seasonal patterns to those not sensitised to each allergen, with some geographical variation. In southern Europe, those sensitised to grass allergens were more likely to report attacks occurred in spring or summer than in winter (OR March/April 2.60, 95\% CI 1.70-3.97; OR May/June 4.43, 95\% CI 2.34-8.39) and smaller later peaks were observed in northern Europe (OR May/June 1.25, 95\% CI 0.60-2.64; OR July/August 1.66, 95\% CI 0.89-3.10). Asthmatics reporting hay fever but who were not sensitised to grass showed no seasonal variations.

Seasonal variations in asthma attacks in young adults are common and are different depending on sensitisation to outdoor, but not indoor, allergens.

Seasonal variation in asthma attacks is associated with sensitisation to pollens and moulds, but not indoor allergens http://ow.ly/nsuRS 


\section{Introduction}

As far back as the fifth century BC Hippocrates noted seasonal variation in exacerbations of asthma [1]. Seasonal patterns have been described for asthma mortality, hospital admissions and emergency department visits [2-5], the variation being ascribed to seasonal variation in exposure to ambient allergens, respiratory infections and meteorological changes $[4,6]$. In older adults, asthma mortality and hospital admissions are more common during the winter months (possibly explained by infections), and in the younger adult population (a "more atopic" generation) are more common in periods of high ambient allergen load (grass in the spring and summer; mould in the late summer and autumn) [7].

However, to date, no large study has described seasonal variation in population-based asthmatics who also have information on IgE sensitisation. Small panel studies suggest asthma severity is worse in the pollen season in those sensitised to grass $[8,9]$ and in winter in those sensitised to house dust mite [10]. Asthmatics presenting to accident and emergency departments in Spain in early summer (May-June) were more likely to be sensitised to grass than those presenting in other months [11]. Similarly, mild, near fatal and fatal asthma has been associated with sensitisation to Alternaria in months where Alternaria levels are high $[12,13]$.

In this report we use information collected from participants in the European Community Respiratory Health Survey (ECRHS), a large multicentre international study of young to middle-aged adults living in differing climatic regions and in countries with marked variation in the prevalence of sensitisation to environmental allergens [14]. The aim is to describe seasonal variation in asthma exacerbations in those who are and are not sensitised to aeroallergens, to quantify the risk and to assess whether seasonal patterns are consistent between countries.

\section{Material and methods}

The ECRHS I [15] recruited a random sample of at least 3000 adults aged 20-44 years, identified from a population-based sampling frame in each participating centre. Each was sent a postal questionnaire and a random sample of responders plus a sample of those with symptoms suggestive of asthma (symptomatic sample) were invited for further tests. The postal survey, the clinical interview (at which skin-prick tests (SPTs) were performed and blood samples taken) and the testing of samples for serum IgE were conducted between 1991-1993.

Overall, 41 centres in 16 countries and on three continents (Europe, North America and Australasia) followed the full protocol. Of the 24115 participants (random and symptomatic sample), 3353 (13.9\%) reported they "ever had asthma". Of the participants that reported they "ever had asthma" 3151 (94.0\%) provided a complete response to the question "Which months of the year do you usually have attacks of asthma?" (with a response of "no" or "yes" to each of the six bimonthly periods: January/February, March/ April, May/June, July/August, September/October and November/December). Overall, 2709 (86\%) had SPTs. In one centre (Iceland), the number of asthmatics with positive SPTs was insufficient for statistical analysis, leaving 2637 asthmatics with information on seasonality and SPTs (2023 with serum specific IgE and total IgE measures) (online supplementary figure S1).

SPTs to Timothy grass, Dermatophagoides pteronyssinus (house dust mite), cat, Cladosporium herbarum, Alternaria alternata, birch and common ragweed were performed using Phazets, lancets precoated with standardised lyophilised allergen extracts (Pharmacia Diagnostics AB, Uppsala, Sweden). SPTs were considered positive if the mean wheal diameter (MWD) was $>0 \mathrm{~mm}$ [16]. Serum samples were tested for specific IgE (Timothy grass, house dust mite, cat and Cladosporium plus birch in Northern Europe, Parietaria in Southern Europe, and ragweed in Australia and the USA) using the Pharmacia CAP System (Pharmacia Diagnostics AB). Sensitisation was considered present if serum IgE was $>0.35 \mathrm{kU} \cdot \mathrm{L}^{-1}$. Due to regulatory and ethical constraints, SPT to Timothy grass was not performed in Germany. Ethical permission to conduct the study was granted by local ethics committees within each participating centre.

For editorial comments see page 898 .

This article has supplementary material available from www.erj.ersjournals.com

Received: June 202012 | Accepted after revision: Jan 042013 | First published online: March 072013

Support statement: Co-ordination of the ECRHS I was supported by a grant from the European Commission. Skin-prick testing with Phazet received grant support from Pharmacia Diagnostics (Uppsala, Sweden). Each local centre was funded by local funding agencies (described in the online supplementary material). C. Canova is funded by the Medical Research Council and Health Protection Agency (G0801056).

Conflict of interest: Disclosures can be found alongside the online version of this article at www.erj.ersjournals.com 


\section{Statistical analysis}

Each participant was considered to have taken part in six surveys: one asking if they experienced asthma attacks in January/February, another in which they were asked whether they experienced attacks in March/April and so on. A marginal logistic regression model for binary outcomes, based on generalised estimating equations, was used to generate the risk of reporting a particular 2-month period was associated with attacks of asthma (with January/February as the reference category). This method, which is appropriate for dealing with longitudinal and other correlated binary response data, generates robust estimators regardless of the specification of the covariance matrix and, as autocorrelation is included in the covariance, coefficients can be interpreted as usual. The bimonthly periods were shifted 6 months forward for Australian and New Zealand centres to allow seasonal comparison across the two hemispheres.

To examine whether these patterns were different in those who were and were not sensitised, an interaction term (positive SPT to specific allergen no/yes $\times$ the six bimonthly periods) was included giving a total of five interaction terms for each model. Where there was evidence of effect modification by sensitisation, analyses were repeated stratified by sensitisation status. Throughout, adjustments for age, sex and sensitisation to the allergens not under assessment (four of house dust mite, grass, cat, Alternaria and birch) were included.

Analyses were conducted within countries, but as there were insufficient data within each country to identify patterns clearly, results from each country were combined using meta-analytical techniques. Risk estimates for each country within each of the three continents were combined in a random effects metaanalysis [17] and heterogeneity tested using the Q statistic and $\mathrm{I}^{2}$. As there was evidence of heterogeneity in Europe, European countries were further divided into central/north Europe and south Europe (defined by $\pm 50^{\circ}$ latitude). As this geopolitical method of division Europe may not fully capture pollen exposures, we also interrogated pollen maps (www.pollenwarndienst.at) to divide countries into those with 1) Poaceae season starting before and after May or June and 2) countries where peak birch season levels were $>70.0$ grains $\cdot \mathrm{m}^{-3}$ (online supplementary table $\mathrm{S} 1-2$ ).

In sensitivity analyses, this was repeated, defining a positive SPT by MWD $\geqslant 3 \mathrm{~mm}$, with sensitisation based on serum IgE measures (using both $>0.35$ and $>0.70 \mathrm{kU} \cdot \mathrm{L}^{-1}$ cut-offs), with the sample restricted to asthmatics who reported symptoms (wheezing, chest tightness, attack of shortness of breath coming on during the day at rest and waking with shortness of breath) or the use of asthma medication in the last 12 months ( $n=2423,92 \%)$, and with inclusion of an adjustment for the month of interview. Effect modification of seasonality of asthma attacks by high total $\operatorname{IgE}\left(>100 \mathrm{kU} \cdot \mathrm{L}^{-1}\right)$ and reported "hay fever or nasal allergies" was also assessed.

All analyses were undertaken in Stata IC 10.1 (Stata software version 10.1; Stata Corp., College Station, TX, USA).

\section{Results}

Table 1 shows the number (range: 43 in Ireland to 387 in Canada), age and sex distributions of participants with self-reported asthma in each country. Of these, 93\% reported "physician diagnosed asthma". The proportion of asthmatics sensitised to each allergen varied between countries in a pattern broadly similar to that previously reported in the general population (table 1) [14]. Allergic sensitisation to allergens associated with vegetation (grass and birch), indoor allergens (cat and dust) and moulds (Alternaria) was prevalent in all countries. However, the prevalence of sensitisation to Cladosporium was low in all countries except the USA $(n=12,18 \%)$, Canada $(n=57,15 \%)$, Sweden $(n=51,14 \%)$ and the UK $(n=46,13 \%)$. Similarly, the prevalence of sensitisation to ragweed was low in most countries except Canada $(n=104$, $27 \%)$, the USA $(n=11,16 \%)$ and the UK $(n=16,4 \%)$. The small number of participants precluded inclusion of the USA in analyses of variation by these two allergens.

Table 2 shows the proportion of asthmatics who, when asked, reported their attacks of asthma usually occurred at specific times of the year and the adjusted odds ratio of reported asthma attacks in each bimonthly period. In most countries, most participants reported seasonal variation in their asthma (range: $47 \%$ Sweden to $86 \%$ Spain; median: $70 \%$ in France, Switzerland, New Zealand). In some countries, there was no clear overall seasonal pattern (e.g. France, Ireland, Germany and Norway), whereas in many countries (e.g. Spain, Italy, Switzerland, Belgium, Sweden, the USA and Australia) a significant increased risk of reported asthma attacks was seen in the spring or summer months (March/April and May/June) compared to winter ones. In contrast, there was an overall decreased risk of asthma in the summer months in the Netherlands, the UK, Canada and New Zealand (i.e. asthmatics reported their attacks of asthma usually occurred in winter). 
TABLE 1 Demographic characteristics and the proportion of asthmatics with positive skin-prick test to each allergen, by country (ordered by latitude)

\begin{tabular}{|c|c|c|c|c|c|c|c|c|}
\hline Country & Subjects $n$ & Females \% & Age & Dust mite & Timothy grass & Cat & Birch & Alternaria \\
\hline Spain & 190 & 53 & $31.7 \pm 7.3$ & $82(43)$ & $53(28)$ & 32 (17) & $11(6)$ & $9(5)$ \\
\hline France & 273 & 51 & $33.1 \pm 7.6$ & 146 (53) & $113(41)$ & $83(30)$ & $33(12)$ & $41(15)$ \\
\hline Switzerland & 122 & 51 & $31.8 \pm 6.7$ & $37(30)$ & $75(61)$ & $37(30)$ & $58(48)$ & $11(9)$ \\
\hline \multicolumn{9}{|l|}{ Northern Europe } \\
\hline The Netherlands & 51 & 49 & $34.3 \pm 7.9$ & $34(67)$ & $16(31)$ & $9(18)$ & $11(22)$ & $2(4)$ \\
\hline Ireland & 43 & 56 & $32.1 \pm 7.0$ & $36(84)$ & $12(28)$ & $7(16)$ & $1(2)$ & $3(7)$ \\
\hline UK & 366 & 57 & $33.2 \pm 7.0$ & 217 (59) & 179 (49) & $131(36)$ & $44(12)$ & $84(23)$ \\
\hline Sweden & 354 & 56 & $32.7 \pm 7.5$ & $107(30)$ & 165 (47) & $219(62)$ & $167(47)$ & $48(14)$ \\
\hline Norway & 60 & 48 & $33.1 \pm 6.6$ & $13(22)$ & $18(30)$ & 16 (27) & 17 (28) & $2(3)$ \\
\hline \multicolumn{9}{|l|}{ North America } \\
\hline Total & 2637 & 55 & $33.2 \pm 7.1$ & 1384 (53) & $1128(44)$ & $943(36)$ & $575(22)$ & $410(16)$ \\
\hline
\end{tabular}

Data are presented as mean \pm SD or n (\%), unless otherwise stated. Centres: Spain (Barcelona, Galdakao, Albacete, Oviedo and Huelva); Italy (Pavia, Turin and Verona); France (Paris, Grenoble, Bordeaux and Montpellier); Switzerland (Basel); Germany (Hamburg and Erfurt); Belgium (Antwerp City and South Antwerp); Netherlands (Groningen, Geleen and Bergen-op-zoom); Ireland (Dublin); UK (Ipswich, Norwich, Cambridge and Caerphilly); Sweden (Uppsala, Umea and Gothenburg); Norway (Bergen); USA (Portland); Canada (Winnepeg, Vancouver, Hamilton, Montreal, Halifax and Prince Edward Island); New Zealand (Wellington, Christchurch and Hawkes Bay); Australia (Melbourne). \#: based on serum IgE measurement.

There was no evidence that sensitisation to house dust mite or cat allergens modified the seasonal pattern of reported asthma attacks in any of the countries or continents ( $\mathrm{p}$-value for interaction of bimonthly period by sensitisation $>0.05, \mathrm{I}^{2}$ for variation between countries $<40 \%$ ) (fig. la and $\mathrm{b}$ ). In the few centres with sufficient data, there was some suggestion of effect modification by having a positive SPT to ragweed (Canada, UK) throughout the summer and early autumn $(\mathrm{p}<0.05$ only in September/October) and by having a positive SPT to Cladosporium in July/August (UK, Sweden and Canada) but formal testing showed this to be below the conventional limits of statistical significance (fig. 1c and d).

In contrast, there was evidence that seasonal variation was modified by sensitisation to grass, birch and Alternaria (online supplementary figures S2-S4 show meta-analysis of the interaction coefficients). In figures $2-4$, the odds of reporting asthma attacks in each bimonthly period are shown, stratified by sensitisation status. There was considerable variation in Europe (for example, $\mathrm{I}^{2}$ for the interaction terms for grass in May/June and birch sensitisation in March/April within Europe were $61 \%$ and 76\%, respectively). When Europe was considered as north and south, or divided based on available average pollen levels over the past 15 years (early/late Poaceae season or by peak birch pollen levels reached) some differences still remained.

In both south and north Europe (fig. $2 \mathrm{a}$ and b), those sensitised to grass were more likely to report that their asthma attacks usually occur in the spring/summer periods than in the winter period, while those who were not sensitised were more likely to report attacks in the winter months. For those who were grass sensitised, the higher risks were in early summer in southern Europe (OR March/April 2.60, 95\% CI 1.703.97; OR May/June 4.43, 95\% CI 2.34-8.39), and by comparison, in northern Europe the peak risks were relatively smaller, occurred later and showed more variation between the countries (OR July/August 1.66, 95\% CI 0.89-3.10; I ${ }^{2}$ 61\%). Similar patterns were seen in Europe when countries were considered to have an early or late grass pollen season (online supplementary fig. S5). In North America (fig. 2c), the pattern was similar to that seen for southern Europe (although all interaction terms $\mathrm{p}>0.05$ ). In Australia and New Zealand (fig. 2d), the effect of grass sensitisation on asthma attacks was more complex, being different in the two countries, and superimposed on an overall decreased risk of attacks during the summer or autumn months. Formal testing for modification of the seasonal pattern by sensitisation to grass was significant $(\mathrm{p}<0.05)$ only in March/April. In all regions, the seasonal pattern of asthma amongst those reporting "hay fever or nasal allergies" (overall, 77\% of asthmatics also reported hay fever) was similar to that seen for grass 
TABLE 2 The proportion of participants with information who reported their asthma attacks occurred at specific bimonthly periods of the year and the adjusted odds ratio of reporting that asthma attacks usually occur in a given bimonthly period by country

\begin{tabular}{|c|c|c|c|c|c|c|c|}
\hline Country & $\begin{array}{c}\text { Asthma attacks at } \\
\text { specific bimonthly } \\
\text { periods } \%\end{array}$ & $\begin{array}{c}\text { OR } \\
\text { Jan/Feb }\end{array}$ & $\begin{array}{c}\text { OR } \\
\text { March/April }\end{array}$ & $\begin{array}{c}\text { OR } \\
\text { May/June }\end{array}$ & $\begin{array}{c}\text { OR } \\
\text { July/Aug }\end{array}$ & $\begin{array}{c}\text { OR } \\
\text { Sept/Oct }\end{array}$ & $\begin{array}{c}\text { OR } \\
\text { Nov/Dec }\end{array}$ \\
\hline Spain & 86 & 1.00 & 1.54 & 0.94 & 0.47 & 0.90 & 1.11 \\
\hline Italy & 85 & 1.00 & 1.54 & 2.44 & 1.10 & 0.81 & 0.81 \\
\hline France & 70 & 1.00 & 0.97 & 1.06 & 0.74 & 0.67 & 0.88 \\
\hline Switzerland & 70 & 1.00 & 1.74 & 2.36 & 1.18 & 1.07 & 0.97 \\
\hline Germany & 76 & 1.00 & 1.05 & 1.15 & 0.95 & 1.05 & 1.15 \\
\hline Belgium & 67 & 1.00 & 1.57 & 2.35 & 1.79 & 2.05 & 1.91 \\
\hline The Netherlands & 75 & 1.00 & 1.00 & 0.37 & 0.34 & 0.85 & 1.09 \\
\hline Ireland & 79 & 1.00 & 0.35 & 0.44 & 0.82 & 0.74 & 1.11 \\
\hline UK & 61 & 1.00 & 0.63 & 0.84 & 0.97 & 0.72 & 1.00 \\
\hline Sweden & 47 & 1.00 & 1.09 & 1.48 & 1.04 & 0.91 & 1.09 \\
\hline Norway & 50 & 1.00 & 0.86 & 0.74 & 1.18 & 0.86 & 0.74 \\
\hline USA & 72 & 1.00 & 0.83 & 2.38 & 1.00 & 1.06 & 0.89 \\
\hline Canada & 79 & 1.00 & 0.70 & 0.81 & 0.80 & 0.79 & 0.91 \\
\hline New Zealand & 70 & 1.00 & 0.71 & 0.45 & 0.37 & 0.44 & 1.00 \\
\hline Australia & 59 & 1.00 & 1.66 & 1.07 & 0.77 & 0.59 & 0.81 \\
\hline
\end{tabular}

Odds ratio coefficients from generalised estimating equations models controlling for repeated individual observations, sex and age. ${ }^{\#}$ : without consideration of sensitisation to aeroallergen; ${ }^{*}$ : bimonthly periods have been shifted 6 months forward to allow comparison with the northern hemisphere. Statistically significant results $(p<0.05)$ are shown in bold.

sensitisation ( $54 \%$ of those with hay fever also had sensitisation to grass) (online supplementary fig. S5). However, this pattern was only present in those sensitised to grass, and not seen in those who reported hay fever but who were not sensitised to grass (fig. 3).

In Europe, asthmatics who were sensitised to birch were more likely to report that their attacks occurred in the spring or summer than in the winter months. The seasonal pattern amongst those who were sensitised to birch was clearly seen in northern Europe (OR May/June 2.94, 95\% CI 1.92-4.50; OR July/August 2.01, 95\% CI 1.38-2.94) (fig. 4b), although there was some variation between countries (e.g. OR May/June 0.87, $95 \%$ CI $\left.0.55-1.37 ; \mathrm{I}^{2}: 72 \%\right)$. The pattern was seen in countries where peak birch pollen levels exceeded 70.0 grains $\cdot \mathrm{m}^{-3}$ (online supplementary fig. S6), but again there was some variation in the magnitude of the effect between countries. Compared to grass sensitisation, the peak risk in this sensitised group occurred earlier in the year (fig $3 \mathrm{~b}$ and fig. 4b). Some seasonal variation was also seen in southern Europe (where birch pollen levels are generally lower). There was no evidence that sensitisation to birch modified seasonal variation of asthma attacks in North America or Australasia (all interactions p >0.05; fig. 4c-d).

Asthmatics who were sensitised to Alternaria were at a greater risk of reporting asthma attacks in May/June and July/August in southern Europe (fig. 5a) and in July/August in north Europe (fig. 5b). There was some evidence of similar seasonal patterns of reporting asthma attacks in North America (fig. 5c) (formal testing for interactions $\mathrm{p}<0.05$ in July/August) and in Australasia (fig. $5 \mathrm{~d}$ ) the pattern was similar to that seen for grass sensitisation.

None of the above observations were substantially altered by changing the definition of a positive SPT (MWD $\geqslant 3 \mathrm{~mm}$ ), by using serum specific IgE to define sensitisation (using a cut off of 0.35 or $0.70 \mathrm{kU} \cdot \mathrm{L}^{-1}$ ), by restricting the sample to those who had asthma symptoms in the past year or by including the month of interview (and SPT) as a potential confounder. Furthermore, high levels of total $\operatorname{IgE}\left(>100 \mathrm{kU} \cdot \mathrm{mL}^{-1}\right)$ did not influence seasonal variations (data not shown).

\section{Discussion}

This large study of $>2500$ young adults with asthma shows that a substantial proportion report seasonal variation in their attacks of asthma, and that the pattern of the seasonal variation is dependent on whether they are sensitised to pollens and moulds, but not indoor allergens. Asthmatics sensitised to grass, birch and Alternaria show very different seasonal patterns to those not sensitised to these allergens. This is most clearly seen for sensitisation to grass, where individuals who are sensitised report more attacks in the summer months 

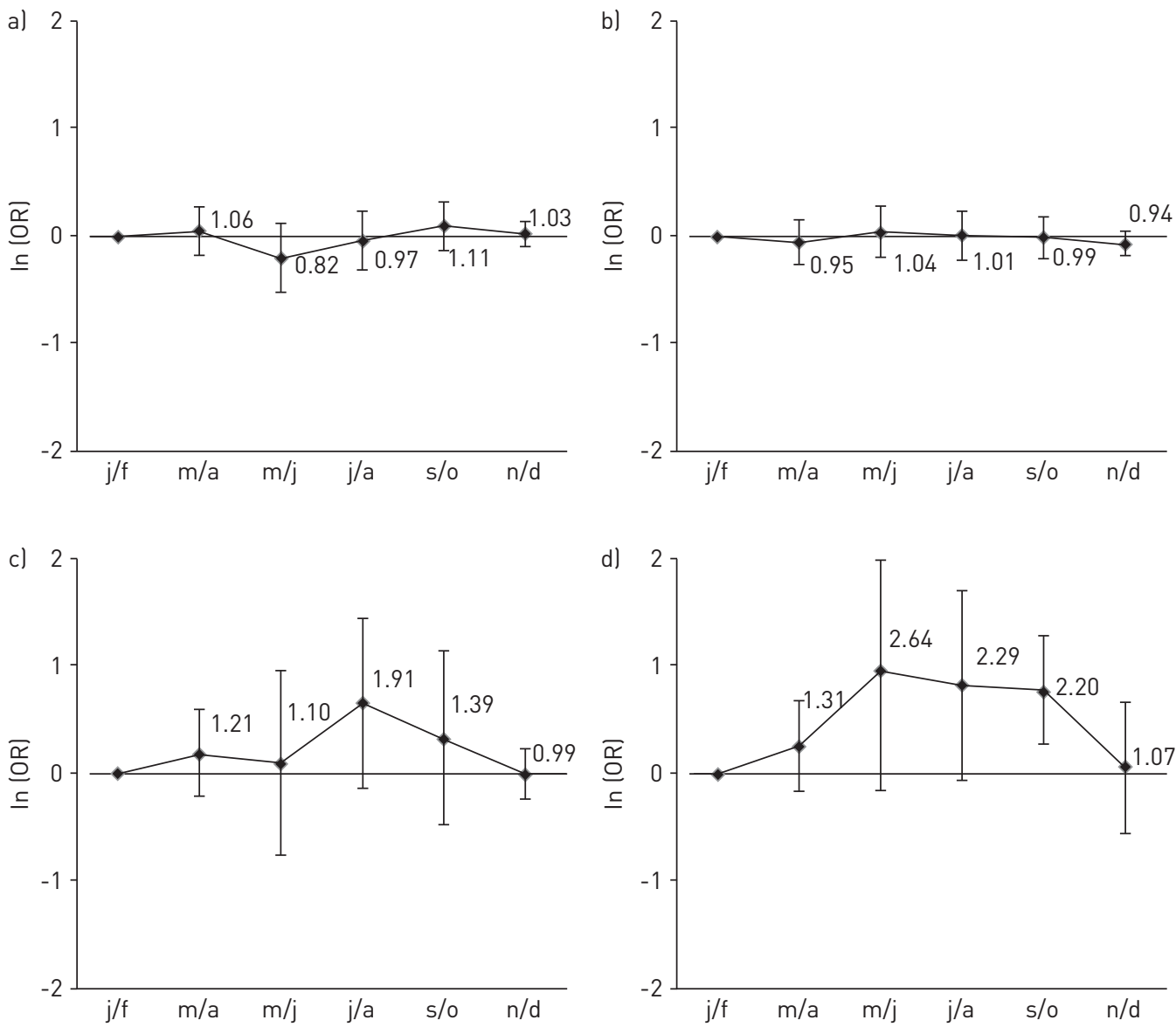

FIGURE 1 The overall adjusted odds ratio (error bars represent 95\% confidence intervals) of asthma usually occurring in each bimonthly period in those sensitised to a) house dust mite in all countries; b) cat in all countries; c) Cladosporium in Sweden, the UK and Canada; and d) ragweed in the UK and Canada. Overall adjusted odds ratios are from meta-analysis of interaction coefficients from generalised estimating equations models conducted within country controlling for repeated individual observations, main effect of relevant allergen and bimonthly periods, sex, age and sensitisation to dust mite (for cat), cat (for house dust mite) and grass, birch and Alternaria. j/f: January/February; m/a: March/April; m/j: May/June; j/a: July/August; s/o: September/October; n/d: November/December.

(most likely related to allergen exposure) and those who are not sensitised report more attacks in the winter months (most likely due to the effects of respiratory infections [6]). Although these patterns are widely recognised by clinicians, to date, no epidemiological study of this scale has described these patterns, or derived risk estimates associated with sensitisation status in representative samples of the asthmatic population.

Beyond the clear relevance for clinical practice, our results provide important baseline information for risk assessment in relation to climate change and may assist in the interpretation of health effects of outdoor air pollution on asthma.

We would expect the seasonal pattern in those who are sensitised to pollens and mould to mirror the patterns of exposure. We do not have complete information on pollen levels in all of our participating centres for the period of data collection (1991-1992). Two groups (the European Academy of Allergy and Clinical Immunology and the International Association of Aerobiology) collated all available pollen data from Europe (1974-1988) [18], which showed peak grass (Poaceae) pollen counts occurred later in northern than southern Europe, and in some countries (e.g. northern Italy) were raised well into September/ October. In Scandinavian countries, the birch pollen season began in May, lasting at least until the end of August, while the season was earlier, shorter and more intense in "southern" Europe. The "average" pollen season over the last 15 years is broadly similar to these patterns (www.pollenwarndienst.at) and more recent European work confirms these temporal and geographical variations in grass pollen [19, 20], birch [21] and mould spore counts (Alternaria and Cladosporium) [22, 23]. However, there is growing evidence that measurement of pollen allergenicity (a subject of research within multicentre initiatives such as the Health 

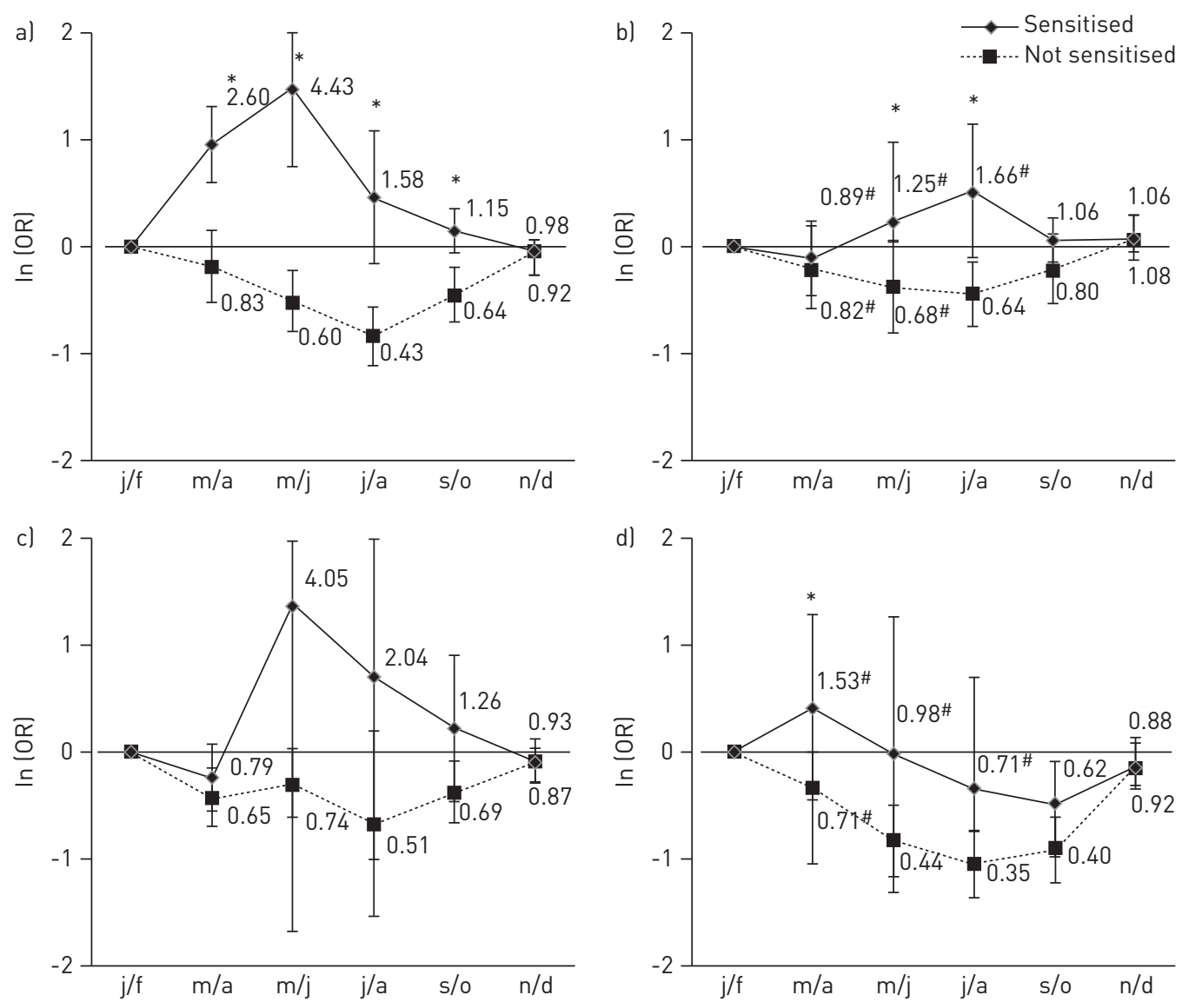

FIGURE 2 The overall adjusted odds ratio (error bars represent 95\% confidence intervals) of asthma usually occurring in each bimonthly period in those sensitised to grass and in those not sensitised to grass in a) south Europe; b) north Europe; c) North America; and d) Australasia (bimonthly periods have been shifted 6 months forward to allow comparison with the northern hemisphere). Overall adjusted odds ratios are from meta-analysis of bimonthly period coefficients from generalised estimating equations models conducted within country controlling for repeated individual observations, sex, age and sensitisation to dust, cat, Alternaria and birch. j/f: January/February; m/a: March/April; m/j: May/June; j/a: July/August; s/o: September/October; n/d: November/December. ${ }^{\#}$ : p-heterogeneity $<0.05 ;{ }^{*}$ : p-value for interaction $<0.05$.

Impacts of Airborne Allergen Information Network; www.hialine.com), rather than pollen counts, may be the relevant exposure to explain allergen associated variations in asthma exacerbations [24].

Our report suggests that mortality and admissions are the "tip of the iceberg" of seasonal variations in asthma. Most asthma treatment guidelines list exposure to seasonal allergens as a potential trigger to asthma attacks [25], and our data support that those with sensitisation to grass, birch and Alternaria (and possibly Cladosporium) may benefit from focussed clinical protocols [26] that increase inhaled treatment during the months of peak exposure to allergen. They may even benefit from desensitisation and immunotherapy ( $2.6 \%$ of asthmatics reported they "had been vaccinated for allergy in the previous 12 month"). Assessment of sensitisation by SPTs and/or serum measures may not be routinely performed in all primary healthcare settings. However, the interpretation of such testing requires understanding of potential crossreactivity and should be carefully considered alongside information on likely exposure. For example, some people may test positive to ragweed in the UK, but ragweed pollen is absent there. Sensitisation probably arises from cross-reactivity with other members of the Compositae (Asteraceae) family (e.g. mugwort). Even though our data suggest that people with positive SPTs to ragweed in the UK and Canada have different seasonal patterns, particularly in late summer, compared to those without positive SPTs (fig. 1d), this might be explained by residual confounding by mould exposure. Similarly, the pattern of variation that we have seen in those who do and do not have positive SPTs to birch in southern Europe may in part be explained by cross-reactivity with other members of the Bet $\mathrm{v}$ 1-family (e.g. hazel and hop-hornbeam) [27]. Asthmatics who also reported hay fever showed an increased risk of reporting exacerbations in the spring and summer months but this was limited to those who were grass sensitised. Although reporting hay fever identifies those at greater risk of spring/summer asthma exacerbations (online supplementary fig. E7), the 

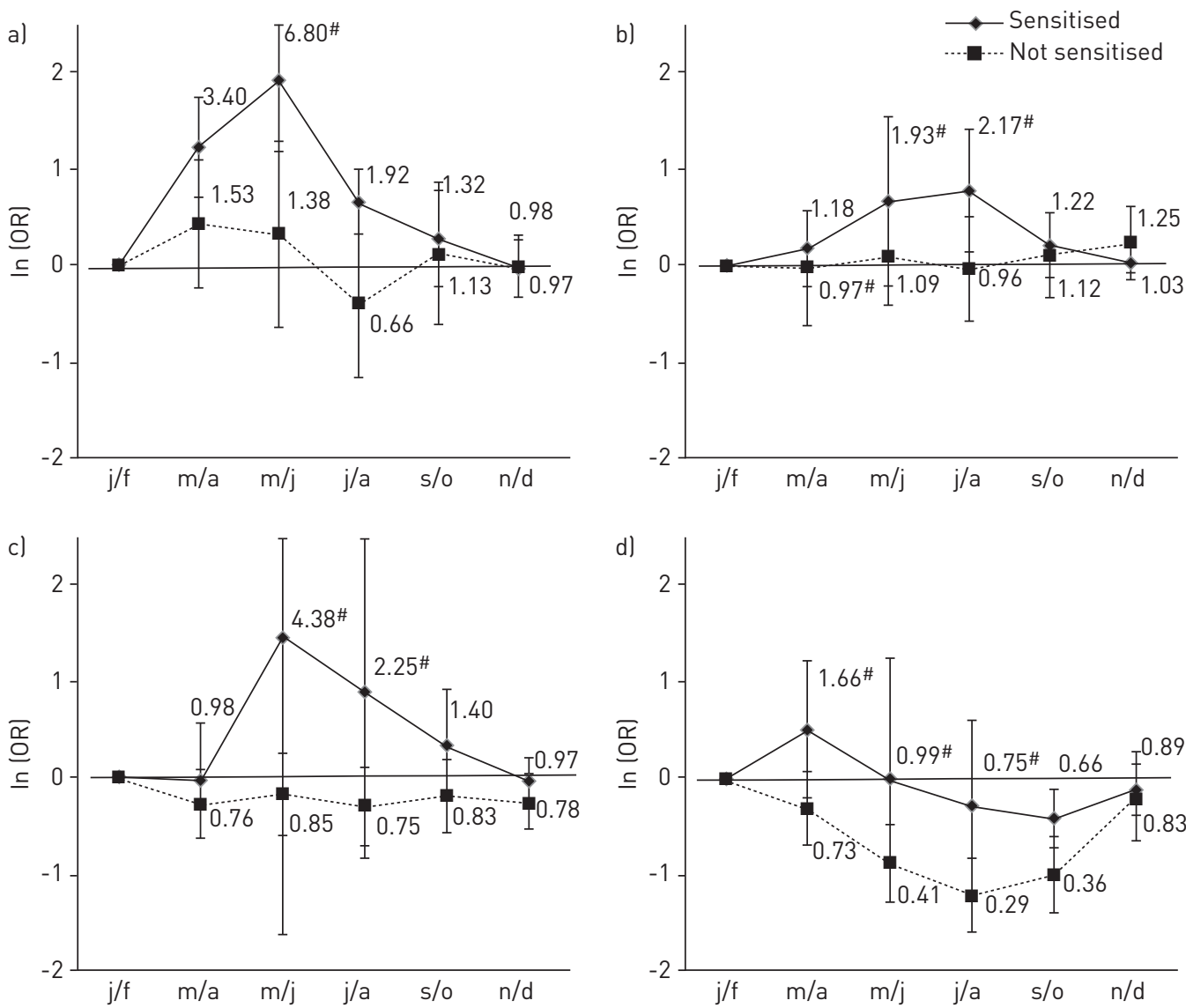

FIGURE 3 The overall adjusted odds ratio (error bars represent 95\% confidence intervals) of asthma usually occurring in each bimonthly period in those with reported hay fever sensitised and not sensitised to grass in a) south Europe; b) north Europe; c) North America; and d) Australasia (bimonthly periods have been shifted 6 months forward to allow comparison with the northern hemisphere). Overall adjusted odds ratios are from meta-analysis of bimonthly period coefficients from generalised estimating equations models conducted within country controlling for repeated individual observations, sex, age (only among subjects with sensitisation to dust, cat, Alternaria and birch data). j/f: January/ February; m/a: March/April; m/j: May/June; j/a: July/August; s/o: September/October; n/d: November/December. \#: p-heterogeneity $<0.05$.

addition of testing for grass sensitisation may be more useful to identify those at risk (fig. 3). Indoor allergens, such as house dust mite and cat, may have a role in determining asthma exacerbations and severity of disease, but our data suggest that those sensitised to indoor allergens have the same seasonal variations as those who are not sensitised to these allergens.

Large time series and ecological studies of asthma mortality and admissions in relation to pollen or mould exposure [7, 28-32] present effect estimates for the entire population and have not included differences in effect in those who are and are not sensitised (the proportion of which varies between countries). The effect of pollen on sensitised individuals may confound the respiratory effects of other outdoor pollutants, particularly ozone (which peaks during the summer months). This could explain the inconsistency in the association of ozone with asthma reported in some time series studies [33, 34]. Possible interactions between air pollutants and aeroallergens and their effect on asthma exacerbations have been investigated in few studies. Individual sensitisation to such aeroallergens might influence the observed effects and explain why such interactions are only seen in some studies [35].

Climate change may lead to more intense and extended pollen or mould seasons with higher absolute levels and increased allergenicity [36, 37]. There may be more thunderstorms, which are known to cause sudden peaks in grass and mould allergen levels and "epidemic asthma" in those who are sensitised [11, 38]. This report provides baseline information showing that those who are sensitised are indeed a subgroup of the population who will be particularly at risk if these climatic changes occur.

The ideal study design to investigate the effects of pollen exposure on asthma exacerbations is a longitudinal or panel study of asthmatics who provide symptom and sensitisation information at regular intervals over a 

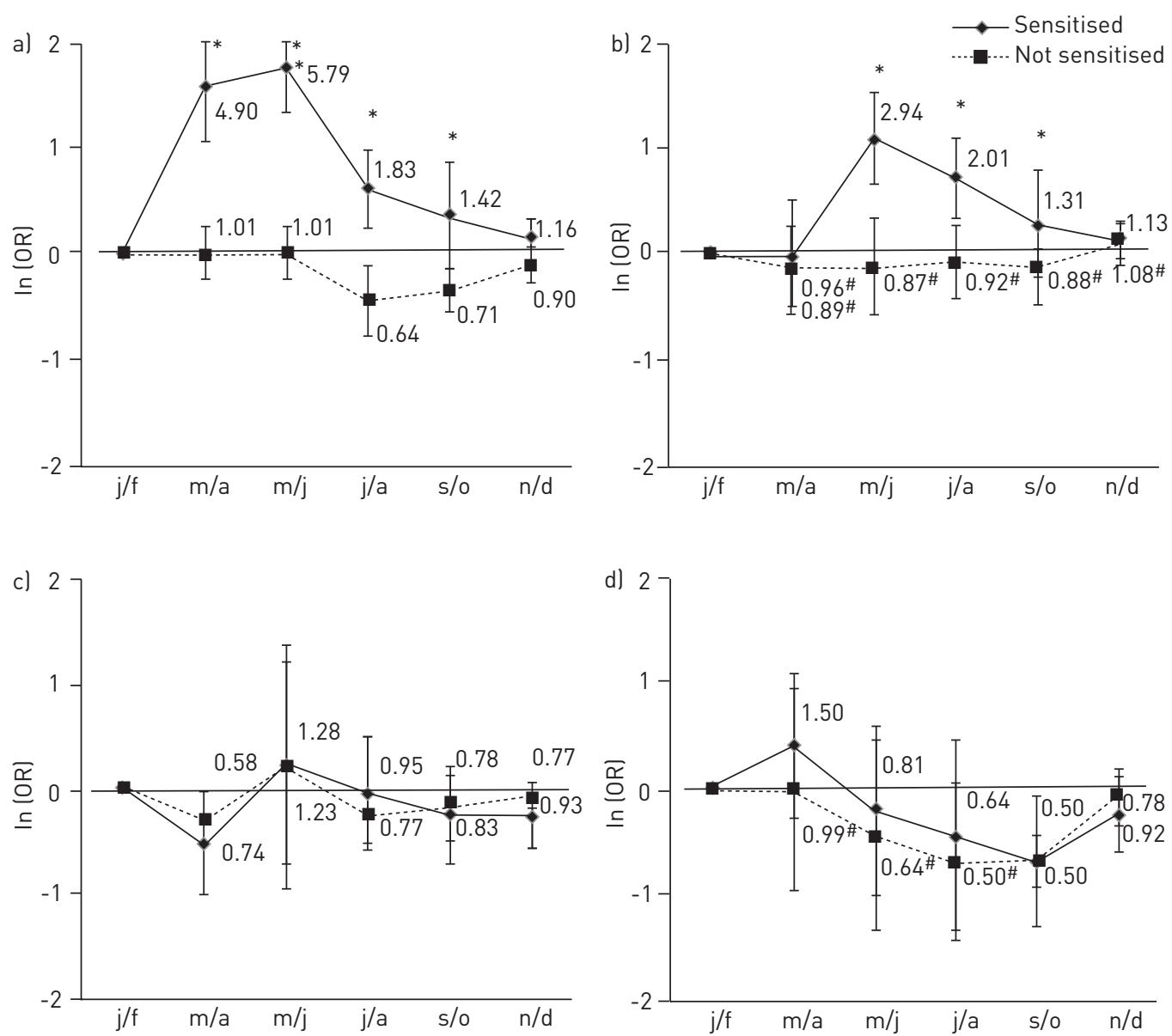

FIGURE 4 The overall adjusted odds ratio (error bars represent 95\% confidence intervals) of asthma usually occurring in each bimonthly period in those sensitised to birch and in those not sensitised to birch in a) south Europe; b) north Europe (the Netherlands and Ireland were not included due to few asthmatics sensitised to birch producing a lack of model convergence); c) North America; and d) Australasia (bimonthly periods have been shifted 6 months forward to allow comparison with the northern hemisphere). Overall adjusted odds ratios are from meta-analysis of bimonthly periods coefficients from generalised estimating equations models conducted within country controlling for repeated individual observations, sex, age and sensitisation to grass, dust, cat and Alternaria. j/f: January/February; m/a: March/ April; m/j: May/June; j/a: July/August; s/o: September/October; n/d: November/December. \#: p-heterogeneity $<0.05$; ${ }^{*}$ : p-value for interaction $<0.05$.

1-year period, but only one large study of this type (on children) has been reported [39]. Although our study design is not optimal, it is, to our knowledge, the only large international study of seasonal variations in population-based asthmatics in whom atopic status has been assessed. Participants were identified from representative community based samples (not from hospital clinics) and even though the vast majority reported a physician diagnosis of asthma, only a third reported using inhaled steroids in the past year (reflecting that they had relatively mild disease [40] and the under-treatment of asthma during the 1990s). We have relied on self-reported seasonality collected at one point in time, which has high face validity but may introduce random error (making it more difficult to identify clear patterns). Systematic error is unlikely as seasonal reporting was not influenced by month of interview or by participants knowing their IgE status (questionnaire was asked before SPT).

Even though our report is based on observations made 20 years ago, similar patterns were still seen in adults who took part in ECRHS II (a subsample of participants included in this report who were followed up in 2000-2002, $\mathrm{n}=1284$, aged 27-54 years at follow-up, 12 countries) who underwent repeat questionnaires and limited serum IgE testing (no SPTs were performed in ECRHS II) (online supplementary fig. E8).

We have described geographical variation in seasonality but, because of the relatively small sample size in some centres, have grouped information from centres to country level, and then regional level. Our regions are thus defined by geopolitics rather than factors that others may consider more relevant (e.g. pollen levels, climate and land usage). 

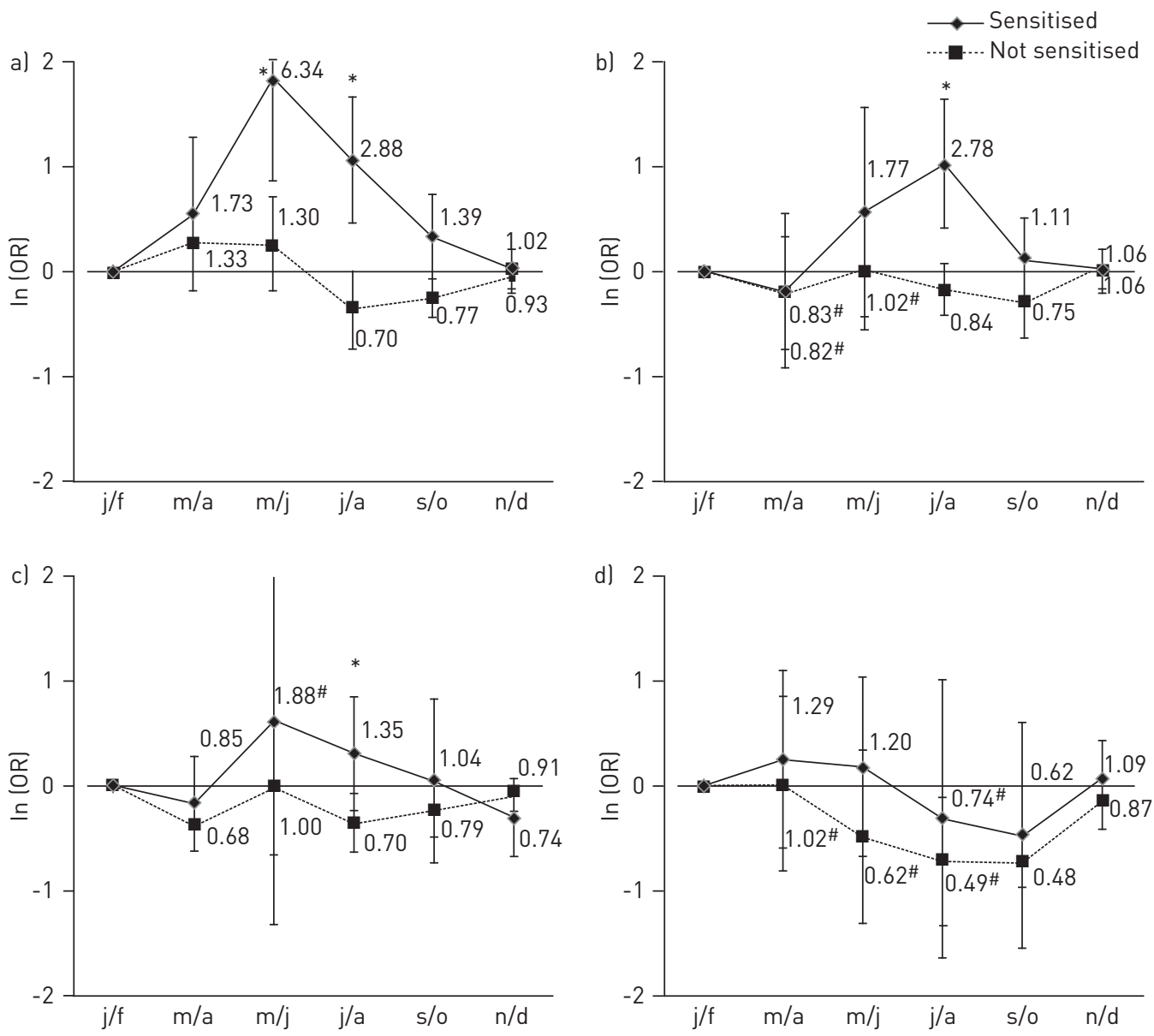

FIGURE 5 The overall adjusted odds ratio (error bars represent 95\% confidence intervals) of asthma usually occurring in each bimonthly period in those sensitised to Alternaria and in those not sensitised to Alternaria in a) south Europe; b) north Europe (the Netherlands, Belgium, Ireland and Norway were not included due to few asthmatics sensitised to Alternaria producing a lack of model convergence); c) North America; and d) Australasia (bimonthly periods have been shifted 6 months forward to allow comparison with the northern hemisphere). Overall adjusted odds ratios are from meta-analysis of bimonthly periods coefficients from generalised estimating equations models conducted within country controlling for repeated individual observations, sex, age and sensitisation to grass, dust, cat and birch. j/f: January/ February; m/a: March/April; m/j: May/June; j/a: July/August; s/o: September/October; n/d: November/December. *: p-heterogeneity $<0.05 ;{ }^{*}$ : p-value for interaction $<0.05$.

In conclusion, we have shown that seasonal variation in asthma attacks in young adults is common and is strongly associated with allergic sensitisation. This is a timely reminder to clinicians to remain alert to seasonal allergens as a potential trigger for asthma attacks in their sensitised patients. Air pollution scientists should strive to include measures of allergen exposure and measures of individual (or at least population levels) of allergic sensitisation in their analyses. Climate change may increase pollen levels and their allergenicity, and also extend pollen seasons; this will probably lead to increased exacerbations in those who are sensitised to these aeroallergens. Large panel studies to better understand and quantify the relationships between exacerbations, allergic sensitisation, directly measured pollen counts and other factors are required.

\section{Acknowledgements}

This paper is dedicated to the memory of Dr Michael ("Mike") Burr.

\section{References}

Hippocrates. Aphorisms III. 19.22.

Khot A, Burn R. Seasonal variation and time trends of deaths from asthma in England and Wales 1960-82. Br Med J (Clin Res Ed) 1984; 289: 233-234.

3 Fleming DM, Cross KW, Sunderland R, et al. Comparison of the seasonal patterns of asthma identified in general practitioner episodes, hospital admissions, and deaths. Thorax 2000; 55: 662-665.

4 Silverman RA, Stevenson L, Hastings HM. Age-related seasonal patterns of emergency department visits for acute asthma in an urban environment. Ann Emerg Med 2003; 42: 577-586. 
Baibergenova A, Thabane L, Akhtar-Danesh N, et al. Effect of gender, age, and severity of asthma attack on patterns of emergency department visits due to asthma by month and day of the week. Eur J Epidemiol 2005; 20: 947-956.

6 Nicholson KG, Kent J, Ireland DC. Respiratory viruses and exacerbations of asthma in adults. BMJ 1993; 307: 982-986.

7 Huynh BT, Tual S, Turbelin C, et al. Short-term effects of airborne pollens on asthma attacks as seen by general practitioners in the Greater Paris area, 2003-2007. Prim Care Respir J 2010; 19: 254-259.

8 Tilles SA, Bardana EJ Jr. Seasonal variation in bronchial hyperreactivity (BHR) in allergic patients. Clin Rev Allergy Immunol 1997; 15: 169-185.

9 Britton J, Chinn S, Burney P, et al. Seasonal variation in bronchial reactivity in a community population. J Allergy Clin Immunol 1988; 82: 134-139.

10 van der Heide S, De Monchy JG, De Vries K, et al. Seasonal differences in airway hyperresponsiveness in asthmatic patients: relationship with allergen exposure and sensitization to house dust mites. Clin Exp Allergy 1997; 27: 627-633.

11 Galan I, Prieto A, Rubio M, et al. Association between airborne pollen and epidemic asthma in Madrid, Spain: a case-control study. Thorax 2010; 65: 398-402.

12 Dharmage S, Bailey M, Raven J, et al. Mouldy houses influence symptoms of asthma among atopic individuals. Clin Exp Allergy 2002; 32: 714-720.

13 O'Hollaren MT, Yunginger JW, Offord KP, et al. Exposure to an aeroallergen as a possible precipitating factor in respiratory arrest in young patients with asthma. N Engl J Med 1991; 324: 359-363.

14 Bousquet PJ, Chinn S, Janson C, et al. Geographical variation in the prevalence of positive skin tests to environmental aeroallergens in the European Community Respiratory Health Survey I. Allergy 2007; 62: 301-309.

15 Burney PG, Luczynska C, Chinn S, et al. The European Community Respiratory Health Survey. Eur Respir J 1994; 7 : 954-960.

16 Chinn S, Jarvis D, Luczynska CM, et al. Measuring atopy in a multi-centre epidemiological study. Eur J Epidemiol 1996; 12: 155-162.

17 Bradburn M, Deeks J, Altman D. Metan - an alternative meta-analysis command (Metan 1.81). Stata Technical Bulletin 2003; 44: 4-15.

18 D’Amato G, Spieksma FTM, Bonini S, eds. Allergenic Pollens and Pollinosis in Europe. Oxford, Wiley-Blackwell, 1991.

19 Emberlin J, Siegfried J, Dominguez-Vilches E, et al. Temporal and geographical variations in grass pollen seasons in areas of western Europe: an analysis of season dates at sites of the European polleninformation system. Aerobiologia 2000; 16: 373-379.

20 D’Amato G, Cecchi L, Bonini S, et al. Allergenic pollen and pollen allergy in Europe. Allergy 2007; 62: 976-990.

21 Emberlin J, Detandt M, Gehrig R, et al. Responses in the start of Betula (birch) pollen seasons to recent changes in spring temperatures across Europe. Int J Biometeorol 2002; 46: 159-170.

22 Stepalska D, Harmata K, Kasprzyk I, et al. Occurrence of airborne Cladosporium and Alternaria spores in Southern and Central Poland in 1995-1996. Aerobiologia 1999; 15: 39-47.

23 Corden JM, Millington WM. The long-term trends and seasonal variation of the aeroallergen Alternaria in Derby, UK. Aerobiologia 2001; 17: 127-136.

24 Buters JTM, Thibaudon M, Smith M, et al. Release of Bet v 1 from birch pollen from 5 European countries. Results from the HIALINE study. Atmospheric Environment 2012; 55: 496-505.

25 Global Initiative for Asthma. Global strategy for asthma management and prevention. www.ginasthma.org/local/ uploads/files/GINA_report_March13.pdf Date last accessed: August, 2013. Date last updated: December, 2012.

26 Yawn BP. Factors accounting for asthma variability: achieving optimal symptom control for individual patients. Prim Care Respir J 2008; 17: 138-147.

27 Hauser M, Asam C, Himly M, et al. Bet v 1-like pollen allergens of multiple Fagales species can sensitize atopic individuals. Clin Exp Allergy 2011; 41: 1804-1814.

28 Dales RE, Cakmak S, Judek S, et al. Influence of outdoor aeroallergens on hospitalization for asthma in Canada. J Allergy Clin Immunol 2004; 113: 303-306.

29 Atkinson RW, Strachan DP, Anderson HR, et al. Temporal associations between daily counts of fungal spores and asthma exacerbations. Occup Environ Med 2006; 63: 580-590.

30 Erbas B, Chang JH, Dharmage S, et al. Do levels of airborne grass pollen influence asthma hospital admissions? Clin Exp Allergy 2007; 37: 1641-1647.

31 Hanigan IC, Johnston FH. Respiratory hospital admissions were associated with ambient airborne pollen in Darwin, Australia, 2004-2005. Clin Exp Allergy 2007; 37: 1556-1565.

32 Raphoz M, Goldberg MS, Garneau M, et al. Associations between atmospheric concentrations of spores and emergency department visits for asthma among children living in Montreal. Arch Environ Occup Health 2010; 65: 201-210.

33 Sunyer J, Spix C, Quenel P, et al. Urban air pollution and emergency admissions for asthma in four European cities: the APHEA Project. Thorax 1997; 52: 760-765.

34 Atkinson RW, Anderson HR, Sunyer J, et al. Acute effects of particulate air pollution on respiratory admissions: results from APHEA 2 project. Air Pollution and Health: a European Approach. Am J Respir Crit Care Med 2001; 164: 1860-1866

35 Cakmak S, Dales RE, Coates F. Does air pollution increase the effect of aeroallergens on hospitalization for asthma? J Allergy Clin Immunol 2012; 129: 228-231.

36 Cecchi L, D’Amato G, Ayres JG, et al. Projections of the effects of climate change on allergic asthma: the contribution of aerobiology. Allergy 2010; 65: 1073-1081.

37 Wolf J, O’Neill NR, Rogers CA, et al. Elevated atmospheric carbon dioxide concentrations amplify Alternaria alternata sporulation and total antigen production. Environ Health Perspect 2010; 118: 1223-1228.

38 Venables KM, Allitt U, Collier CG, et al. Thunderstorm-related asthma - the epidemic of 24/25 June 1994. Clin Exp Allergy 1997; 27: 725-736.

39 Dellavalle CT, Triche EW, Leaderer BP, et al. Effects of ambient pollen concentrations on frequency and severity of asthma symptoms among asthmatic children. Epidemiology 2012; 23: 55-63.

40 Cazzoletti L, Marcon A, Janson C, et al. Asthma control in Europe: a real-world evaluation based on an international population-based study. J Allergy Clin Immunol 2007; 120: 1360-1367. 